\title{
MEMÓRIAS DE HOMOSSEXUALIDADES, ESCOLARIZAÇÕES E HOMOFOBIAS
}

\author{
Fernando Guimarães Oliveira da Silva ${ }^{1}$, José Antonio de Souza ${ }^{2}$ \\ ${ }^{1}$ Doutor em Educação pela Universidade Estadual de Maringá - UEM. Professor do Programa de Pós-graduação em \\ Educação da Universidade Estadual de Mato Grosso do Sul - UEMS, Paranaíba, MS. E-mail: \\ fernando.oliveira@uems.br. \\ ${ }^{2}$ Doutor em Letras pela Universidade Estadual de Londrina - UEL. Professor do Programa de Pós-graduação em \\ Educação da Universidade Estadual de Mato Grosso do Sul - UEMS, Paranaíba, MS.
}

\section{RESUMO}

É uma pesquisa de pós-graduação em educação que objetiva reviver memórias de sujeitos do gênero masculino e homossexuais sobre violências físicas e não físicas experienciadas durante o período escolar. Metodologicamente, orientamo-nos pelo viés das pesquisas pós-críticas em educação por se tratar de assuntos que desestabilizam modelos universalizantes que usam explicações que têm a essência e a natureza como elementos classificadores das pessoas. Essa abordagem prevê pluralizar sentidos sobre a questão da construção social acerca do gênero e das sexualidades para melhor contextualizar como os sujeitos participantes da pesquisa inserem suas memórias discursivas. Dada a concepção dessa abordagem, nosso estudo propôs a participação a um grupo do Facebook denominado de Grupo Gay Facebook Brasil (GGFBR), onde postamos um convite para movimentar a participação. Contamos com oito sujeitos que possuem uma variedade de diferenças (faixa etária, região brasileira, trajetórias de vida) que associadas à questão do atendimento escolar nos trazem uma diversidade de assuntos para que a questão das sexualidades e suas performatividades sejam validadas em ambiente escolar. Como conclusão, a sexualidade emerge como um assunto que também compõe a construção da subjetividade, o que pode levar demandas necessárias para se discutir equidade, ética e pluralidade de constituição.

Palavras-Chave: Memória. Homossexualidades. Escolarizações.

\section{MEMORY OF HOMOSEXUALITIES, SCHOOLIZATIONS AND HOMOPHOBIAS}

\section{ABSTRACT}

It is a postgraduate research in education that aims to relive memories of male and homosexual subjects about physical and non-physical violence experienced during the school period. Methodologically, we are guided by the bias of post-critical research in education by dealing with issues that destabilize universalizing models that use explanations that have essence and nature as classifying elements of people. This approach intends to pluralize meanings about the issue of social construction about gender and sexualities in order to better contextualize how the research participants insert their discursive memories. Given the conception of this approach, our study proposed participating in a Facebook group called the Gay Facebook Brazil Group (GGFBR), where we posted an invitation to move participation. We have eight subjects who have a variety of differences (age group, Brazilian region, life trajectories) that associated with the issue of school attendance bring us a diversity of issues so that the issue of sexualities and their performativities are validated in the school environment. In conclusion, sexuality emerges as a subject that also makes up the construction of subjectivity, which may lead to the necessary demands to discuss equity, ethics and plurality of constitution.

Keywords: Memory. Homosexualities. Schooling.

\section{MEMORIA DE HOMOSEXUALIDADES, ESCUELAS Y HOMOFOBIAS}

\section{RESUMEN}

Es una investigación de posgrado en educación que tiene como objetivo revivir recuerdos de sujetos masculinos y homosexuales sobre la violencia física y no física experimentada durante el período escolar. 
Metodológicamente, nos guiamos por el sesgo de la investigación poscrítica en educación al tratar temas que desestabilizan los modelos universalizadores que usan explicaciones que tienen esencia y naturaleza como elementos clasificadores de las personas. Este enfoque intenta pluralizar los significados sobre el tema de la construcción social sobre género y sexualidad para contextualizar mejor cómo los participantes de la investigación insertan sus recuerdos discursivos. Dada la concepción de este enfoque, nuestro estudio propuso participar en un grupo de Facebook llamado Gay Facebook Brazil Group (GGFBR), donde publicamos una invitación para mover la participación. Tenemos ocho temas que tienen una variedad de diferencias (grupo de edad, región brasileña, trayectorias de vida) que asociadas con el tema de la asistencia escolar nos traen una diversidad de temas para que el tema de las sexualidades y sus performatividades se validen en el entorno escolar. En conclusión, la sexualidad emerge como un tema que también constituye la construcción de la subjetividad, lo que puede llevar a las demandas necesarias para discutir la equidad, la ética y la pluralidad de la constitución.

Palabras clave: memoria. Homosexualidades. Escolaridad.

\section{INTRODUÇÃO}

Vozes veladas, veludosas vozes, Volúpias dos violões, vozes veladas, Vagam nos velhos vórtices velozes Dos ventos, vivas, vãs, vulcanizadas. Tudo nas cordas dos violões ecoa E vibra e se contorce no ar, convulso...

Tudo na noite, tudo clama e voa Sob a febril agitação de um pulso (CRUZ E SOUZA, 1951).

A epígrafe indica que as vozes estão em todos os lugares, elas pulsam, se contorcem, são jogadas nos ventos, se fazem vivas, ecoam em diferentes direções, vagam, clamam... Indica também que as vozes representam necessidades dos sujeitos. Isso significa, por sua vez, que não podem ser apagadas da história. Escutá-las se faz necessário. Pode ser que não do jeito que elas querem ser ouvidas, uma vez que os enquadramentos e as molduras criadas sobre o existir desconsideram o que é diferente. As vozes aqui trabalhadas ecoaram vidas de sujeitos homossexuais no cenário escolar conjugadas com sentidos sociais, econômicos, políticos e culturais de um tempo, o momento em que suas vidas tiveram a oportunidade de se chocar com a instituição escolar. As vozes precisam ser enunciadas para cumprir o sentido necessário da construção de práticas que rompam com todo um percurso educacional cujo itinerário sóciohistórico tem sido de processos de exclusão às vezes impossíveis de serem corrigidos.

É o caso, por exemplo, de sujeitos que se apresentam diferentes porque performam 0 gênero e a sexualidade de modo distante do enquadramento moldado à matriz heterossexista como princípio de norma. Ao ocuparem o espaço escolar, pessoas com orientação sexual, identidade de gênero e sexuais diferentes produzem o questionamento de concepções curriculares, rotinas escolares, práticas pedagógicas. Nos trazem preocupações sobre uma série de atitudes que colocam sob suspeita a lógica reprodutora de desigualdades, opressão e discriminação. Leva-nos a indagar se as passagens que eles fizeram pelas escolas produziram mudanças ou atacaram as expressões de gênero e sexualidades que manifestaram naquele momento.

A pesquisa que segue trata-se de um estudo realizado junto ao Programa de Pósgraduação em Educação, nível de mestrado, da Universidade Estadual de Mato Grosso do Sul (UEMS), defendido em 2015, sob o título de 'Vozes desveladas... Memórias de homossexuais sobre práticas escolares'. Nele, procurou-se acessar memórias de diferentes cenas de violências físicas, não físicas e práticas de combate à homofobia que poderiam ser realizadas pelas unidades escolares experienciadas pelos sujeitos participantes da pesquisa. Objetivamente, acredita-se que seja necessário colocar vidas homossexuais de diferentes locais do país em contato com requisições sociais no âmbito da educação. Para isso, o recorte apresentado refere-se às memórias de violências físicas sofridas pelos sujeitos homossexuais em ambiente escolar.

\section{DELINEAMENTO METODOLÓGICO}

Ao situar o/a leitor/a sobre o que movimenta esse estudo quando se pretende realizar conversas científicas sobre expressões de gênero e sexualidades que pairam no espaço 
escolar, a ideia é que diferentes experiências de vida de décadas diferentes possam se cruzar para colocar novas demandas para as práticas docentes, institucionais e discursivas que estão veiculando nesse ambiente.

De princípio, a abordagem que orienta as discussões tratadas caminha no terreno dos estudos pós-críticos em educação. Meyer e Paraíso (2014) apresentam aspectos das metodologias de estudos pós-críticos. Para elas, as metodologias são construídas em meio a lutas, questionamentos, movimentos de incertezas: "[...] afastamo-nos daquilo que é rígido, das essências, das convicções, dos universais, da tarefa de prescrever e de todos os conceitos e pensamentos que não nos ajudam a construir imagens de pensamentos potentes para interrogar e descrever-analisar nosso objeto" (MEYER; PARAÍSO, 2014, p. 18-19).

Abordar um jeito de pesquisar oportuniza utilizar da criatividade como uma forma de questionar a verdade. Verdades universais sobre sexo, gênero e sexualidades estão em discurso. Tais verdades materializam formas de existências que são consideradas padrões, deslegitimando as diferentes expressões de sujeitos cujos traços e marcadores sociais da diferença se cruzam. Uma construção da verdade que nos impõe um pensamento dominante sobre essa existência dentro dos enquadramentos normais, fazendonos acreditar que a diferença que conduz a maior parte dos erros que pessoas diferentes vivenciam. Como se as dificuldades que um homossexual enfrenta é porque ele escolheu e precisa lidar com o fardo social disso.

Há que se permitir questionar discursos oficializados de que as pessoas homossexuais devem ser culpabilizadas pelos seus fracassos. Transformar sentidos para que avancem e não fiquem cristalizados na história cultural ou que se fazem reatualizados. Os estudos como esse que associam questões da diferença com o gênero e a sexualidade propõem desestabilizar verdades historicamente criadoras de padrões de normalidade, normatividades e desigualdades entre as pessoas, contribuindo assim para se repensar muitas situações como a atenção ofertada por uma variedade de locais, equipamentos públicos e etc. É o que pretende os estudos de abordagem pós-crítica.

Segundo Meyer e Paraíso (2014, p. 19), o uso de uma ou mais abordagens teóricas que entrecruzam diferentes assuntos que deslocam as teorias críticas por novos conceitos, novos acessos as verdades, denomina-se pesquisas póscríticas, citam assim algumas questões pertinentes a esse campo que faz incluir a presente pesquisa nesse cenário de abordagem: "[...] multiculturalismo, pensamento e diferença, estudos culturais, estudos de gênero, estudos étnicos e raciais e estudos queer, entre outros".

Contextualizada a abordagem pós-crítica, - uso da arqueologia foucautiana foi indispensável para se colher as memórias dos sujeitos participantes da pesquisa. Na obra a Aqueologia do saber, Foucault (1987) diz que para compreender a originalidade histórica dos discursos é preciso submetê-lo ao estudo minucioso para capturar suas projeções futuras e intencionalidades. $O$ trabalho proposto ao/a pesquisador/a, nesse caso, relaciona-se a colher sentidos contidos nos discursos para estabelecer suas relações com os regimes de verdade instituídos.

Ao colher as memórias de violências físicas dos participantes, a arqueologia do saber criará um mapeamento de sentidos sobre a homossexualidade. Sentidos pejorativos da sociedade da época de escolarização do sujeito serão visíveis porque fizeram parte do tratamento dado pelas unidades escolares aos estudantes. Vão ressoar assim, sentidos sobre negação da diferença, verdades sobre a sexualidade e expressão de gênero considerada normal para a época de escolarização, além de apresentar possibilidades de reconhecimento dessa diferença na escola.

Partindo dos estudos foucaultianos, Deleuze (2005) diz que a ideia de criação dos estudos arqueológicos vincula-se à construção de uma nova ocupação profissional, a de um arquivista cuja atribuição será o uso dos enunciados. Segundo Deleuze (2005), o método arqueológico é rigoroso e estruturado e parte do enunciado para colher sentidos lançados pelos sujeitos, sendo estes por sua vez, reflexos ou não de um contexto social em que se situa ou acredita situar.

O enunciado para Deleuze (2005) pode ser repetido, já as frases podem ser recomeçadas ou reatualizadas. Os enunciados são repetidos porque possuem "[...] o mesmo espaço de distribuição, a mesma repartição de singularidades, a mesma ordem de locais e de posições, a mesma relação com o meio instituído [...]" (DELEUZE, 2005, p. 22). O ato de contar uma memória permite compreender um cenário escolar que reconhecia ou não o sujeito 
homossexual naquele momento. Acessar assim a regularidade de sentidos que se tinha sobre esse sujeito, justificando o porquê não faziam parte das atividades escolares ou o porquê não existiu situações pedagógicas que combatessem a homofobia.

Então, para acessar os discursos nas memórias dos sujeitos, ao registrarem tais informações os acontecimentos discursivos manifestam alguns elementos que dominavam os sentidos da época em que estudavam. Foucault (1972, p. 34) destaca que a análise dos acontecimentos discursivos:

[...] não está, de maneira
alguma, limitada a
semelhante domínio; e,
por outro lado, o recorte
do próprio domínio não
pode ser considerado
como definitivo, nem
como válido de forma
absoluta; trata-se de uma
primeira aproximação que
deve permitir o
aparecimento de relações
que correm o risco de
suprimir os limites desse
primeiro esboço.

Com a oportunidade de terem suas vozes escutadas, os autores das memórias discursivas preservam o passado na articulação com o presente para entender como suas memórias estão em movimento e é possível ou não encontrar transformações relevantes que reconhecem os avanços ou que também reconheçam retrocessos.

Para conhecer tais sujeitos, realizou-se um estudo de grupos da rede social Facebook para analisar o potencial de participação que poderia acontecer. $O$ grupo encontrado foi $O$ Grupo Gay Facebook Brasil (GGFBR). Em contato com o moderador do grupo realizou-se alguns questionamentos para conhecer a viabilidade da pesquisa. Dentre os questionamentos, a informação obtida caracterizou que o grupo foi criado em 2011 e que não é resultante de um coletivo ou movimento social organizado. 0 moderador relata que o grupo foi criado para divulgar informações pertinentes às pessoas LGBTs.

Àquela época de realização da pesquisa, em 2015, o grupo tinha um quantitativo de 2.094 (duas mil e noventa e quatro) participantes, a entrada dos/das participantes é possível se alguém já pertencente ao grupo convidar via rede social, caracterizando-se como um grupo secreto. A descrição do objetivo do grupo é identificada:

O Objetivo deste grupo fechado é unir o público gay do Facebook em um único lugar com o intuito de divulgar informações, utilidades, fazer amigos, entre outros. $E$ acreditem: UNIÃO FAZ A FORÇA e, unidos, muito mais fácil lutarmos por espaço, leis e tudo que merecemos. Agora, se ninguém se mexer, as coisas vão ficar onde estão e não adianta reclamar depois (GGFBR, 2015).

Observa-se que o uso da rede social, Facebook, oportuniza um encontro com informações da vida social do grupo de homossexuais bem como chama a atenção para algo necessário que é a mobilização pelo engajamento sociopolítico. Sabendo disso, realizou-se um mapeamento de informações postadas no grupo para identificar o que o grupo àquela época se preocupava.

1) Eventos locais com apresentações de drags, gogoboys, cantores e Djs famosos;

2) Publicações sobre o quadro político brasileiro por conta da eleição presidencial;

3) Críticas sobre o grupo se tornar apenas espaço de promoção de eventos e propagandas;

4) Vídeos satirizando o modo como os homossexuais são vistos pelos heterossexuais e

5) Publicações sobre a luta contra discursos de ódio (SILVA, 2015, p. 61).

Desse modo, registra-se a preocupação com a formação política dos sujeitos homossexuais presentes no grupo. De diferentes formas manifestaram suas preocupações sociais com o cenário de vida possível para pessoas homossexuais. Após caracterização do grupo pesquisado, a estratégia para coleta de sujeitos foi possível por meio de um post na página do 
Facebook do grupo. $\mathrm{Na}$ postagem, foram indicadas as informações sobre o objetivo da pesquisa, a unidade de formação que ela estava vinculada, o nome do pesquisador e orientador, e-mail e prazo para o devido retorno. Oito sujeitos participaram prontamente e possuem as seguintes caracterizações:

Memória 1 - 56 anos, concluiu o ensino médio antes de 1979 em Mato Grosso do Sul (MS);

Memória 2 - 27 anos, concluiu o ensino médio depois de 2001 em MS;

Memória 3 - 29 anos, concluiu o ensino médio depois de 2001 em São Paulo (SP);

Memória 4 - 30 anos, concluiu o ensino médio na década de 1990 em SP;

Memória 5 - 35 anos, concluiu o ensino médio na década de 1990 em MS;

Memória 6 - 34 anos, concluiu o ensino médio depois de 2001 em SP;

Memória 7 - 27 anos, concluiu o ensino médio depois de 2001 em MS e

Memória 8 - 38 anos, concluiu o ensino médio na década de 1990 em MS.

Diante das caracterizações, temos um sujeito acima de 50 anos e sete com idades entre 27 e 38 anos, colocando questões socioculturais diversas para a pesquisa. Diferentes elementos sociais, políticos, culturais dos momentos que estudaram ressoam compreensões da homossexualidade que podem refletir sobre a permanência escolar. A questão do Estado que os sujeitos concluíram o ensino médio sinaliza preocupações, nota-se que cinco concluíram no Estado de Mato Grosso do Sul e três em São Paulo. Sujeitos homossexuais de outras regiões não se sentiram atraídos pelo convite no GGFBR, mas diferentes sujeitos das cinco regiões brasileiras foram marcados nos comentários de nosso post no grupo.

Apesar das questões que envolvem traços socioculturais das regionalidades sul-matogrossenses e paulistas não serem destaques das análises dos dados, considerá-las pode disparar inúmeras problematizações acerca de explicações que justificam eventos de homofobia no ambiente escolar na época de escolarização dos participantes da pesquisa que apresentamos, bem como de situações homofóbicas recentemente encontradas em escolas dessas regiões que adquiriram outros vieses de violências.

No contexto das análises, as memórias de M8 não serão consideradas porque o autor delas não trouxe experiências específicas, considerando a possibilidade de não participação ou não exposição das memórias, informando apenas idade e alguns dados de permanência escolar. Além disso, nem todos os sujeitos apresentam experiências de violências físicas, sendo apenas as memórias dos sujeitos 3, 4 e 6 que concluíram o ensino médio durante a década de 1990 e início do século XXI. Colocando assim que tais experiências são recentes.

Recebido os e-mails, procedemos com a categorização de memórias pertinentes às situações de violência física, não física e as práticas escolares de combate à homofobia. 0 procedimento eleito para categorização das memórias nessas três dimensões envolveu a leitura de Rios (2009). Segundo o autor, por meio de estudos psicológicos e sociológicos sobre preconceito e discriminação foi possível afirmar que a homofobia se manifesta por meio do uso da força física e não física. A violência física ocorre por meio de práticas de discriminação direta, onde Rios (2009) interpreta como intencional e a violência não física, compreendida como indireta e não intencional, referindo-se aos aspectos simbólicos de uma segregação e aversão às diferenças que se legitimam no cerceamento $e$ apagamento dos direitos sociais.

Rios (2009, p. 72) enfatiza que a manifestação da homofobia por meio da violência física é a forma "[...] mais visível e brutal, atinge diretamente a integridade corporal, quando não chega às raias do homicídio". Com base nesse raciocínio de Rios, analisaram-se os aspectos reaviados em memórias de discriminação que "[...] ocorre sempre que distinções, exclusões, restrições ou preferências anulam ou prejudicam o reconhecimento, o gozo ou o exercício em pé de igualdade de direitos humanos e liberdades fundamentais nos campos econômico, social, cultural ou em qualquer campo da vida pública" (RIOS, 2009, p. 73), violência (envolvendo questões físicas, sexuais e não simbólicas) e as práticas escolares.

Mesmo que durante os processos de escolarização dos sujeitos da pesquisa a escola atua na perspectiva da pedagogia do armário, como salienta Junqueira (2013), a partir da reprodução dos parâmetros da heteronormatividade, as inspirações científicas que nos orientam encontram terreno na necessidade de colocar vidas que passaram por diferentes processos de invisibilização no centro da discussão. 
RESULTADOS E DISCUSSÕES: histórias, sentidos e educações da vida homossexual nas escolas

Apressadamente pode parecer que é anticientífico (ou sem confiabilidade) falar de histórias de sujeitos homossexuais. Principalmente se o registro das memórias evidencia sentimentos, sensações de perdas, privilegiar recordações dos ecos do passado que nos auxiliam a melhor interpretar o presente. Entretanto, constata-se que, ao trabalhar com os discursos apensos em memórias - usando narrativas de um questionário e com isso retomando experiências de vida escolar -, demonstra de algum modo, sentidos de emoções vivenciadas que violentas, por sua vez, oferta espaço de voz para aquilo que se acreditava irrelevante.

Narrar uma história do passado na articulação com o presente visa recorrer aos significados do presente para entender problemas sofridos no passado. Precisava de um espaço onde as vozes do sofrimento que poderiam ser inauditas àquela época possam movimentar todo um cenário que apagou tais dificuldades para fazê-las vivas no presente. Os sujeitos homossexuais falam de violências físicas vividas e reconstroem num movimento contínuo uma reinterpretação do passado de seu processo de escolarização para auxiliar na reformatação da ação docente e institucional da escola no trato com as questões do gênero e da sexualidade.

Nesse sentido, as memórias narradas buscam retomar a constituição histórica de cada um como sujeito e construir novos possíveis para o agora de si e também de outras pessoas que passam/passaram pelo mesmo problema da violência física em razão da homossexualidade: "[...] memória é, portanto, sempre esquecimento, pois é interpretação de algo que passou; passado que se faz presente; presente que, a todo momento, já é futuro" (CORACINI, 2007, p. 16).

Ao acessar o inventário de arquivos das memórias dos sujeitos homossexuais, vêem-se vestígios de determinadas condições de produção de um discurso. Utilizar palavras para dar nome às vivências pessoais contidas nos arquivos desses sujeitos expressa que o que foram e sentiram não são meras palavras sem sentido. Como diz Coracini $(2007$, p. 25$)$, ao realizar um movimento de dizer sobre si, o sujeito tem contato com "[...] exercícios de escritura, em que o sujeito se inscreve com seu traço singular num movimento de ausência-presença". Significa dizer que tais experiências nos constituem no interior de diferentes espaços sociais.

No caso da escola, se a forma de tratamento à época de suas escolarizações se apresentava hostil possivelmente a compreensão de liberdade que paira na experimentação dos direitos sexuais não se fazia reconhecida nos discursos oficiais. Nota-se que a sexualidade àquela época era - pode ser que ainda o é tratada como algo de foro íntimo e que não pode ser colocada em discurso. Enunciar suas experiências permitiu que os sujeitos apresentassem fatos, verdades e até mesmo situações de experiências que poderiam ser inibidas para evitar exposições mais amplas. Por conta disso, o exercício de realizar uma narrativa de um fato visa "[...] anular, silenciar, apagar uma vida, assim como pode dela e nela construir uma identidade, que se transforma na verdade do sujeito, deixando uns na penumbra do esquecimento e outros na evidência" (CORACINI, 2007, p. 25)

Adentrar nas histórias de vivência das homossexualidades dos sujeitos participantes do GGFBR oportunizou enfatizar experiências de violência física tais como as que foram narradas pelas memórias 3,4 e 6 , como dito anteriormente. Assim, o que se cria não é uma afirmativa finalíssima e generalizada de que todo homossexual sofra/sofreu violência física na escola, mas tais experiências somadas a outras, trazem informações significativas do real e mobiliza uma leitura (mesmo que provisória) de alguns motivos que explicam a homofobia em ambiente escolar. Propõem identificar as razões do sentido que propiciaram como que tais violências aconteciam.

Apesar do uso do conceito discriminação direta e indireta para compreender as violências físicas e não físicas nas considerações sobre homofobia de Rios (2009), acredita-se, segundo os estudos de Borrillo (2010), que a instrumentalização do sentido também é relevante para problematizar o assunto da homofobia. Segundo Borrillo (2010), o conceito de homofobia é uma manifestação arbitrária que consiste em designar o sujeito da homossexualidade como contrário, inferior ou anormal. A partir dos sentidos culturalmente introduzidos no cenário social, a ideia da diferença como algo ruim capilariza todo o sentido sobre a sexualidade diferente, reduz possibilidades para as manifestações advindas das 
diferenças produzidas por esse desejo, tornandoo fora do universo comum dos humanos.

As diferentes manifestações de discriminação que se manifestam em práticas de cerceamento do uso de direitos sociais, acessos a bens e serviços e também as violências instituídas "[...] desempenha um papel importante na medida em que ela é uma forma de inferiorização, consequência direta da hierarquização das sexualidades, além de conferir um status superior à heterossexualidade, situando-a no plano natural, do que é evidente" (BORRILLO, 2010, p. 15).

Junqueira (2013) confirma que a escola age na manutenção da heteronormatividade. Para isso, segundo o autor, a escola coloca os/as estudantes com expressões diferentes de gênero e de sexualidades no armário, tornando suas vivências no terreno do silêncio e da anormalidade.

\begin{abstract}
A pedagogia do armário interpela a todos/as. Ora, o "armário", esse processo de ocultação da posição de dissidência em relação à matriz heterossexual, faz mais do que simplesmente regular a vida social de pessoas que se relacionam sexualmente com outras do mesmo gênero, submetendo-as ao segredo, ao silêncio e/ou expondo-as ao desprezo público. Com efeito, ele implica uma gestão das fronteiras $d a$ (hetero)normalidade (na qual estamos todos/as envolvidos/as e pela qual somos afetados/as) e atua como um regime de controle de todo o dispositivo de sexualidade (JUNQUEIRA, 2013, p. 286, grifos do autor).
\end{abstract}

A vigilância das experiências de gênero e sexualidade encontra na escola uma forma eficaz de manutenção da heterossexualidade. A pedagogia do armário (JUNQUEIRA, 2013) é uma forma de invisibilizar e invalidar experiências não heterossexuais para que elas não passem a ser legitimadas como possíveis de serem vividas. Como se a censura fizesse parte de experimentações da vida em que o gênero e a sexualidade não são compatíveis com a norma hetero. Segue nas próximas linhas a análise das memórias constituídas em processos de relação com a heteronorma presente no ambiente escolar.

\section{Memória 3: "A escola foi um ambiente de desrespeito e não tratou $o$ assunto das violências com ações educativas de educação sexual" \\ É o que se evidencia na história da} Memória 3:

Já sofri assédio e até
abuso no ensino
fundamental, 5 a série e 6 a
série, onde alguns alunos
cerca de dois a três
mexiam comigo sempre
com xingamentos,

brincadeiras de mau gosto, passadas até de mão nas nádegas e teve até um caso onde fui trancado no banheiro com um dos alunos que me obrigou a fazer sexo oral nele (SILVA, 2015, p. 91).

Observa-se a complexidade do assunto para o âmbito educacional, uma vez que dimensão do problema vivido impressiona. A memória 3 aponta com suas experiências o que considera abuso, assédio e violência sexual. Tomando como referência a análise de Rios (2009) sobre a questão da violência física, acredita-se que $o$ ato sexual forçado representa um contato físico. No entanto, revela-se uma violência sexual que se produziu em ambiente escolar.

Notoriamente, a experiência da memória 3 traz uma série de problematizações. Dentre as quais, considera-se para essa análise como relevante: a) a questão dos reflexos disso na constituição da subjetividade homossexual e b) a ação preventiva que a escola possui no trato com a educação sexual emancipatória e livre de pensamentos conservadores sobre a sua experimentação, principalmente porque há o uso da temporalidade "sempre" para expressar que as violências se faziam presentes na escola.

$\mathrm{Na}$ compreensão de Foucault (1987), Vigiar e Punir, a escola enquanto uma instituição age fielmente por meio de instrumentos tecnológicos que disciplinam os corpos diferentes a partir da naturalização das práticas de violências 
instauradas contra os sujeitos homossexuais. Expressa assim, o silenciamento realizado por ela frente às violências narradas pelos sujeitos no período da década de 1990 e início do século XXI. Com isso, a escola pretende o controle das operações do corpo das crianças e adolescentes por meio da pedagogia eleita para realização das ações escolares e docentes.

Implica reconhecer que os métodos empregados para vigiar a sexualidade visavam conter os corpos para que não experimentassem desejos dissidentes das normas impostas. Conforme iam tolhendo sensações e desejos, implicitamente, as relações sociais refletiam nas escolas, demarcava a linha entre o permitido e o proibido, realizando sanções como o descomprometimento com situações de violências sexuais contra homossexuais. Para Rios (2009), a naturalização das práticas de violências que aconteciam tanto no nível da discriminação com apontamentos pejorativos quanto nas violências físicas praticadas demonstra a relação umbilical entre heterossexismo e homofobia.

Rios (2009) ressalta que independente da complexidade da intenção implícita ou explicita é notável que se trata de um assunto que lesiona direitos humanos. $\mathrm{O}$ autor chama a atenção para o fato de que o enfrentamento dessas práticas de naturalização da homofobia nas escolas precisa ser censurado e há que se tomar muito cuidado para não cair na reprodução involuntária. Diante disso, as piadas ressoam vulgar o modo como elas utilizam palavras pejorativas para inferiorizar a sexualidade: "[...] a discriminação é fruto de medidas, decisões e práticas aparentemente neutras, desprovidas de justificação e de vontade de discriminar, cujos resultados, no entanto, têm impacto diferenciado perante diversos indivíduos e grupos, gerando e fomentando preconceitos e estereótipos inadmissíveis" (RIOS, 2009, p. 76).

Louro (2009) anunciava, nas primeiras edições de seu estudo a partir de perspectivas foucaultianas, Gênero e sexualidade na educação: uma perspectiva pós-estruturalista, que ao se inventar a homossexualidade o poder iniciou a adoção de um conjunto de práticas intencionais ou não que construíram explicações infundadas para normatizar a heterossexualidade como princípio-fim dos desejos dos corpos. Conquistaram a hegemonia das explicações sobre as questões das funcionalidades biológicas dos corpos, mas esqueceram de enfatizar que os aspectos culturais tornam tais explicações passíveis de serem aceitáveis ou não.
Louro (2009) denunciou que a construção das explicações culturais sobre os corpos normais baseou-se em aspectos religiosos que guiaram ciências como a medicina e a área do direito. Institucionalmente, diferentes locais iniciaram práticas de regulamentação de discursos que oferecessem experiência no âmbito da matriz heterossexista. Sexo, gênero e sexualidade começaram a se produzir numa linha explicativa das funcionalidades dos corpos, dando sustentação à heterossexualidade como norma.

Supõe-se, segundo essa lógica, que todas as pessoas sejam (ou devam ser) heterossexuais - daí que os sistemas de saúde ou de educação, o jurídico ou o midiático sejam construídos à imagem e à semelhança desses sujeitos. São eles que estão plenamente qualificados para usufruir desses sistemas ou de seus serviços e para receber os benefícios do Estado (LOURO, 2009, p. 90).

A partir daí as considerações sobre a constituição das subjetividades passam a ser formatadas no contexto da matriz heterossexista. As diferenças de subjetividades construídas sob outros modelos de sexualidades e expressões do gênero consideravam-se sem validade e legitimidade pelas relações em que o poder adquiria expressiva força.

As memórias do sujeito 3 podem não constituir fielmente o passado, mas sim os arquivos informados continuamente na reconstrução desse passado que são ressignificados com elementos do presente. Quando esses sujeitos visualizam-se diferentes conseguem emitir notas valorativas sobre suas existências despregadas de padrões estabelecidos pela matriz heterossexista institucionalmente propagada. Permite, assim, conforme aponta Guatarri e Rolnik (1996, p. 17 ), cartografar a sensibilidade da diferença produzida em um modo de se construir uma subjetividade criativa: "Uma singularização existencial que coincida com um desejo, com um gosto de viver, com uma vontade de construir o mundo no qual nos encontramos, com a instauração de dispositivos para mudar os tipos de sociedade, os tipos de valores que não são os nossos." 
Sofrer com a negação da singularidade de sua subjetividade não foi permitida pelos outros que propagavam sentidos de uma heterossexualidade compulsória, como vimos em Louro (2009). Seguindo a reflexão de Louro (2009), os aspectos institucionais articulados com a análise de Guatarri e Rolnik (1996), propõem encontrar elementos que constituem 0 compromisso social da pesquisa em educação que agregam práticas discursivas regularizadas nas memórias dos participantes homossexuais que fizeram com que seus corpos e desejos fossem vistos como um perigo aos/às que ocupam um lugar entrelaçado pelos estatutos normativos impostos sobre sexualidade e expressões do gênero.

Para Oliveira Junior e Maio (2017), o apagamento de discussões sobre questões LGBT nas escolas está ligado ao fato de que as políticas públicas educacionais criadas para combater a homofobia têm materiais impróprios para a faixa etária da infância e adolescência segundo uma leitura moralista da sexualidade. Com essa compreensão, Oliveira Junior e Maio (2017) se propõem a discutir o retorno de aspectos tradicionalistas que visam a todo custo tornar a escola sem vínculo com a realidade dos sujeitos que a ela pertencem.

Oliveira Junior e Maio (2017) justificam essa problemática a partir dos processos de descontinuidades que os governos federais assumem no trato com a criação de políticas educacionais.

Se podemos considerar a escola como um agente primordial no processo de formação do ser social, possibilitando o exercício de uma cidadania plena, como prerrogativa, se faz necessária a inserção de temas que possuem grande impacto e relevância na vida social, que insistentemente desafiam princípios democráticos e éticos por meio da regulação e manutenção de injustificáveis e distintos prejuízos sociais como a diversidade sexual e o combate e prevenção da violência contra pessoas LGBTQIA (OLIVEIRA
JÚNIOR; MAIO, 2017, p. 14).

Os autores apontam que partir dos elevados índices de violências que atacam a vida de pessoas LGBT é uma forma de evidenciar a necessidade de tornar o assunto parte do cotidiano escolar. Criar formas de enfrentar a cultura do desagendamento das políticas públicas de combate à homofobia a partir de dados cruéis de matança da vida LGBT é uma forma de colocar a diferença que permeia os aspectos de gênero e de sexualidades como possíveis de serem enunciadas, ditas, faladas sem causar tanto medo e aversão.

\section{Memória 4: "Escola como ambiente descompromissado e desapoiador, contribuindo para a naturalização das homofobias vividas"}

$\mathrm{Na}$ memória 4, por exemplo, o uso de comportamentos transgressivos representava uma forma de responder às situações de homofobia que vivia. Segundo M4, tais situações ocorriam o tempo todo, ser motivo de piadinhas, apontamentos, olhares preconceituosos próprios do estigma que demarcou a sua diferença. Hoje, visualiza que tais comportamentos foram mecanismos de defesa para assegurar sua permanência naquele ambiente.

Sua memória narra:

No ano seguinte, as
sétimas séries se
unificaram e formaram
uma única oitava e o
inferno voltou. Fiquei
rebelde, bagunceiro e
comecei a fazer coisas que
nunca faria. O que eu fazia
era tentando me esquivar
da perseguição dos
meninos. Um moço da
minha classe morava aqui
perto do bairro. Em vários
momentos, ele tirava o seu
pênis pra fora nas
brincadeiras de rua para
me mostrar e eu ficava
sem reação. Sentia que ele
queria algo comigo, mas
na sala de aula depois ele
me zoava. Fiquei
estigmatizado por ser gay
na escola toda. Mas
sempre fui mesmo um
tanto delicado, afinal a
minha educação era


rigorosa. Na oitava série isso foi um burburinho. Tudo isso chegava nos ouvidos de minha mãe que foi na escola diversas vezes brigar e a diretora prometeu tomar providências e nada disso aconteceu (SILVA, 2015, p. 94).

Os pontos principais problematizados na memória 4 referem-se: a) mecanismos individuais de defesa da homofobia escolar; b) naturalização do excesso das violências não físicas (piadas, exposições do preconceito e apontamentos vexatórios); c) apoio familiar no trato com as situações de violências não físicas acontecidas; d) sensação de descomprometimento da escola com a vida homossexual.

$O$ assunto do excesso de exposição se faz presente também na memória do quarto sujeito. Há o processo de reconhecimento da diferença por parte, às vezes, do sujeito homossexual, mas a negação da legitimidade disso para os grupos aos quais fazem parte. A negação e o silenciamento diante da violência que enfrentam homossexuais cotidianamente no ambiente escolar representa um dos processos de como tais vidas são fadadas ao fracasso, ao erro e a desimportância social. Reflete e muito, segundo Dinis (2011), a omissão diante das cenas de violência verbal e física que sofrem os/as estudantes.

Dinis (2011) diz que no nosso país a homofobia é um dos últimos preconceitos evidentes e que pouco consegue ampliar pautas políticas de discussões sobre a sua criminalização. Expressa assim que tal preconceito é comumente parte do cotidiano escolar e compartilhado, sobretudo pelos/as profissionais da educação. Finaliza em seu estudo que os/as professores/as precisam ser encorajados/as a assumir a responsabilidade pelas vidas de pessoas lésbicas, gays, bissexuais e trans.

O tratamento hostilizado reconhecido pela Memória 4 somada à ausência de preocupação da escola amplia a relevância social das memórias para que os discursos reproduzidos pelos/as professores/as e outros/as profissionais da escola sejam problematizados. Mesmo em situações que os/as responsáveis familiares representam apoio e proteção, quando não expulsam seus/suas filhos/as de casa, ainda assim o enfrentamento da sociedade e das instituições sociais foi difícil.

O sentido desse apagamento é uma forma de contribuir para que esses sujeitos se sintam anormais, com recursos escassos para, assim, impedirem que suas vidas sejam referências de uma vida possível. É como se tais vidas fossem inúteis para a sociedade se resolvessem se constituir em outros ambientes distantes dos enquadramentos moralmente aceitos, assunto discutido por Butler (2011). A autora traz uma compreensão da vida como precária. Filosoficamente, a autora se dispõe a compreender o que faz uma vida ser inscrita como precária para a sociedade?

Significa pensar, conforme aponta Butler (2011), que nas relações sociais assumimos responsabilidades com as outras pessoas. Desse modo, o tempo todo nossas vidas chocam-se com a autoridade moral, com a autoridade que tem o poder de definir o modelo enquadrado como normalmente aceito para existir. Ter uma expressão do desejo sexual fora da matriz heterossexista faz essa vida ser interpretada como precária.

Nessa relação com o outro, emerge a sensação de que estamos na estrutura do discurso. O discurso pode ou não fazer sentido para mim, "[...] não apenas quando nos reportamos ao Outro, mas que, de alguma forma, passamos a existir no momento em que o discurso nos alcança, e que algo de nossa existência se prova precária quando esse discurso falha em nos convencer" (BUTLER, 2011, p. 15). O contato feito com a autoridade moral não procede de minha reflexividade, ou melhor, não tive autonomia para decidir sobre ela: "Ela chega até mim de um lugar desconhecido, de forma inesperada, involuntária e não planejada. $\mathrm{Na}$ verdade, ela tende a arruinar meus planos e, se meus planos são desfeitos, isso pode muito bem ser um sinal de que a autoridade moral pesa sobre mim" (BUTLER, 2011, p. 15).

Dito assim, as experiências da vida em que foi possível encontrar dificuldades em ambiente escolar por ser homossexual resultam do contato com a moral ${ }^{1}$ definida. A confluência de diferentes discursos propostos pelas experiências de silenciamento da escola frente ao tratamento hostil vivido pelos sujeitos

\footnotetext{
${ }^{1}$ Para o/a leitor/a que decida aprofundar conhecimentos sobre como somos envolvidos/as pelas construções morais, sugerimos leitura da obra Relatar a si mesmo: crítica da violência ética de Judith Butler (2015).
} 
homossexuais faz perceber o quanto as coisas ditas expõem regimes de verdades e de poder que fabricam formas existenciais. Mostra, por um lado, a liberdade de poder falar sobre esses assuntos sem preocupações com a intensidade da fobia como aconteciam antigamente e, por outro, de perceber a gravidade do problema para a constituição de sofrimentos do presente.

Memória 4 adiciona:

Na formatura da oitava, foi realizada uma grande festa num salão de um clube. Todos olhavam para mim, e cochichavam, os pais olhavam para mim e para a minha mãe. Eu fui incumbido de entregar um presente a uma professora após a entrega dos certificados. Quando recebi o meu, minha mãe fez sinal para ir até ela e me disse: "vamos embora, estão todos rindo de sua cara". Eu disse que não porque era minha formatura e ela nervosa me deu um tapa no rosto e me arrastou pelo braço para fora do clube. Lembro que chorei muito. Por isso depois dessa formatura, todas as outras que passei, chorei aliviado por me sentir um vitorioso e hoje ser bem resolvido e aceito (SILVA, 2015, p. 97).

Pontos para se destacar na memória 4: a) preconceitos de violências não físicas; b) família não consegue lidar com o preconceito, gerando desapoios; c) homofobia familiar; d) a ideia de sujeito em contínua mudança que utiliza as aprendizagens de vida do passado para melhor lidar com dificuldades do presente. Tais pontos confluem na adoção de práticas escolares que tenham condições de oferecer respaldo a crianças e adolescentes que se expressam com práticas de gênero e sexualidades opostas aos regimes heterossexistas.

Mesmo que inicialmente cita que a família se preocupava com a amplitude do excesso da exposição vivida, o sujeito da memória 4 deixa explícito uma negação da condição de homossexual que ele expressava. Conduz assim a ideia de contraditoriedade do sujeito no discurso, à opacidade do discurso que ora remete a certezas, ora incertezas e inverdades. Duas situações, então, serão destacadas como pontos problematizadores: a) uma refere-se aos desapoios familiares; b) e a outra, refere-se ao movimento de rever-se enquanto sujeito. Ao utilizar dessa memória para encontrar-se com outras experiências que the fizeram romper com as violências sofridas, o sujeito da memória 4 se coloca em movimento de mudanças e transformações contínuas.

O preconceito vivido reflete na família também. Ocorre uma vergonha social se a família absorve os efeitos produzidos pelos olhares de desprezo. Todo relato realizado se faz em meio às relações sociais, ele adquire sentido a partir do conjunto de informações mobilizadas para encontrar sentido à história de si que é narrada. Nos estudos de Borrillo (2010), a homofobia é interpretada como algo complexo e de diferentes expressões, desde piadinhas vulgares que inferiorizam o "menino femininilizado" e a "menina masculinizada", revestindo-se também de formas brutais de extermínio.

Nota-se que há atribuição de uma sexualidade incompleta e secundária aos homossexuais, Borrillo (2010) aponta que no âmbito da esfera privada a luta do/da homossexual pelo reconhecimento é mais intensa, solicitando uma equivalência à da heterossexualidade. A homofobia nesse caso, segundo o autor, refere-se ao medo de que a homossexualidade seja reconhecida, uma angústia de que a fronteira entre essas duas expressões da sexualidade seja completamente transposta ou que se entrecruzem.

A despeito da homofobia familiar, Schulman (2012) concorda com Borrillo (2010) ao mencionar que as dimensões e especificidades dos atos são amplas e possuem graus variados de desrespeitos, violências e crueldades. No entanto, a autora coloca que a intervenção e apoio de terceiros para amenizar a imensidão do ato representa a possibilidade de superação dos efeitos causados pela homofobia familiar. $\mathrm{O}$ apoio relaciona-se à capacidade de produzir resistência, uma vez que o reconhecimento social da condição de pessoas LGBTs, em geral, é muito problemático.

Schulman (2012) compreende a necessária atuação de terceiros/as para que a homofobia familiar tenha um enfrentamento mais consciente. Isso é importante quando não se tem lugar para escapar em meio aos 
apagamentos que acontecem da homossexualidade em diferentes espaços públicos e sociais. Quando a sociedade não acredita que tem que intervir na família para mudar esse processo ou quando a família acredita que é intocável essa discussão, há uma relação dialógica de opressão (SCHULMAN, 2012).

Ao olhar para o passado por meio da memória, o sujeito 4 revê sua condição e analisa aspectos de uma sociedade que o tornou sinônimo de uma estranheza sem iguais. 0 repúdio aos traços femininos encontrados em suas atitudes foi evidente. Vê-se que a condição feminina também é vista pelo ideal sexista como inferior, principalmente porque a supremacia do masculino sobre o feminino se faz evidente nas relações sociais. Então, um sujeito inicialmente enquadrado como masculino terá reduzidas as possibilidades de ter comportamentos femininos e se ter vários instrumentos disciplinares agirão para assegurar que essa diferença seja interpretada como impossível de ser experimentada.

Infelizmente, no caso da memória do sujeito 4, por conta do excesso da exposição que seu filho sofria aquele momento, a mãe se sentiu envergonhada e optou por abandonar o evento da formatura, utilizando da força física para interromper a exposição que sofria. Demonstra que $o$ ato de homofobia familiar torna-se presente na vida de crianças e adolescentes que expressam práticas sociais estereotipadas como do gênero oposto. Representa - e muito - os desapoios familiares e/ou de terceiros/as.

Por outro lado, é evidente também o heteroterrorismo como uma reiteração de tecnologias discursivas com o uso de objetos (brinquedos, roupas, sapatos...) que desde as primeiras idades educam as crianças para desempenharem com êxito um gênero. É o que trata Bento (2011, p. 551), a autora expõe que a pedagogia dos gêneros hegemônicos "[...] tem como objetivo preparar os corpos para a vida referenciada na heterossexualidade, construída a partir da ideologia da complementaridade dos sexos. As "confusões" nos "papéis" provocam, direta e imediatamente, "perturbações" na orientação sexual, supõem os defensores do binarismo".

Nesse processo contínuo de emprego do heteroterrorismo, como assinala Bento (2011), a construção de uma subjetividade enquadrada por modelos previstos vai se constituindo. Papéis, comportamentos e atitudes consideradas adequadas para o gênero masculino ou feminino vão se alimentando na estranheza com que alguns comportamentos vão sendo tolhidos. $O$ que fica patente é a eliminação do diferente, do considerado anormal em um corpo que precisa sofrer com práticas corretivas, assim a invisibilidade do diferente anuncia a sua morte.

Coracini (2007) diz que o que somos e o que pensamos estão carregados de dizeres alheios. Isso demonstra a incongruência como resultante da constituição dos sujeitos por meio de experiências que formalizam uma ideia de si na interlocução com a imagem que os outros criam dele. Nesse processo de constituição da subjetividade ou há uma vinculação à norma ou a resistência que produz o diferente.

Assunto interessante de ser destacado trata-se da vivência homofóbica no período de escolarização que contribui para a produção subjetiva na fase adulta. A pesquisa de Queiroz (2018) realizou entrevistas semi-estruturadas com 10 homens cisgêneros ${ }^{2}$ homossexuais com idade entre 18 e 30 anos da região manauara sobre a homofobia em idade escolar. Com enfoque na análise de conteúdo, Queiroz (2018) enfatiza duas categorias possíveis que ressoaram em seu estudo. A primeira se refere à vivência das homofobias, aspecto no qual foi possível encontrar sofrimentos por conta de seus corpos e desejos e contrariar a perspectiva heterocêntrica das escolas que estudaram, contribuindo para a permanência das práticas ligadas à homofobia.

O segundo aspecto citado por Queiroz (2018) trata-se das implicações psicossociais da época de escolarização que também refletem na atualidade, como por exemplo: os sujeitos criaram mecanismos de defesa frente à iminência de possíveis ataques ou não de homofobia; tornaram os sujeitos mais empáticos e menos produtores de violências, preconceitos, estereótipos. Apesar da investigação de Queiroz (2018) estar vinculada à área da Psicologia, entende-se que o ambiente escolar é produtor de um espaço de sofrimento que reflete na construção da subjetividade pela via da diferença.

Dependendo da forma como tais experiências são vivenciadas, os sujeitos vítimas da homofobia podem constituir uma linha expressiva de subjetividade em que o ambiente escolar não seja um local de proteção, acolhida e amparo, passando a representar um local de

\footnotetext{
2 Jaqueline de Jesus (2012, p. 10) caracteriza pelo termo cis: “[...] as pessoas que se identificam com o gênero que lhes foi atribuído quando ao nascimento".
} 
conflitos, violência e expulsão compulsória de pessoas LGBT. No caso do sujeito de M4, há a compreensão de que as violências vividas no passado de seu período escolar auxiliaram para que ele compreendesse suas escolhas no presente e criasse movimentos de ruptura que $o$ levaram a superar a homofobia vivida na época escolar.

M4 teve uma experiência que acreditou exitosa, considerando que outros aspectos sociais, econômicos e culturais não eram tão precários em sua vida, diferentemente de outros/as escolares homossexuais que não possuem as mesmas possibilidades de superação. Assunto relevante de se pontuar, uma vez que vidas de sujeitos homossexuais de estratos sociais vulneráveis possuem condições precárias de superação da dimensão potencialmente cruel da homofobia no ambiente escolar e em outras instituições sociais públicas.

\section{Memória 6: "Os homossexuais são anormais, por isso são "bode expiatório" e punidos pelas suas diferenças"}

A memória de M6 narra situações de exposições vexatórias e violências físicas no ambiente escolar: mandado a carta, mas em produto dele estar flertando todos os dias, na janela da minha sala. Em resumo fui remanejado do período noturno para o matutino. Saindo as pressas da diretoria, passando pela calçada da escola, vários meninos $\mathrm{e}$ meninas subiam no muro, e nada falavam só olhavam com olhares acusadores $\mathrm{e}$ riam sem parar. Bom, mas não há mal que dure para sempre, não é mesmo? Engano! No dia seguinte, lá estava eu de "vida nova". E pra minha surpresa só tinha se passado 8 horas e todos já sabiam o que tinha ocorrido no dia anterior. Dos males o menor, eu já tinha aprendido a lição; NADA DE CARTAS! (SILVA, 2015, p. 101)

$\mathrm{Na}$ carga discursiva das memórias do sujeito 6, observa-se: a) sujeito homossexual como motivação de brincadeiras pejorativas e violências físicas que desvalorizam violentamente a vida desse sujeito como passível de ser preservada e reconhecida como vivível; b) punição do sujeito homossexual; c) sentimento de anormalidade que se potencializava nas relações com as outras pessoas. No conjunto discursivo da análise da memória do sujeito 6 , cabe salientar que a ideia de anormalidade se faz presente e fiel à ampliação de barreiras para que esse sujeito tenha sua condição reconhecida no ambiente escolar.

Como bem compreende Foucault (2003), em $A$ vida dos homens infames, a ideia de corpo anormal e infame é assujeitado a uma sociedade que define regimes de verdade sobre aspectos necessários para se ter uma vida moralmente normal. As existências que foram consideradas sem significado para 0 poder tiveram a oportunidade de serem silenciadas ou produzir resistências no contato com as redes de poder.

O poder que espreitava essas vidas, que as perseguiu, que prestou atenção, ainda que por um instante, em suas queixas e em seu pequeno 
tumulto, e que as marcou com suas garras, foi ele que suscitou as poucas palavras que disso nos restam; seja por se ter querido dirigir a ele para denunciar, queixar-se, solicitar, suplicar, seja por ele ter querido intervir e tenha, em poucas palavras, julgado e decidido (FOUCAULT, 2003, p. 203).

Se a vida de sujeitos homossexuais não adquire sentido nos espaços que eles estão, consequentemente a rede discursiva utilizou de uma série de sentidos nas instituições sociais para que as possibilidades de existências desses sujeitos fossem apagadas ou tidas como não necessárias. O sujeito infame é visto como aquele que contraria o discurso das existências consideradas adequadas e respeitosas.

$\mathrm{Na}$ leitura foucaultiana a respeito da anormalidade, Foucault (2010) aponta que os discursos que são disseminados em diferentes instituições possuem raízes histórico-culturais em aspectos religiosos. Uma vez que tais sentidos permearam a constituição de leis, pedagogias e o sistema médico, eles possuem capilaridade nas relações sociais e servem como modelos para enquadrar os corpos das pessoas. Sobretudo, para reconhecer se elas têm possibilidades de fazer parte ou não dos espaços sociais.

Ao analisar documentos de loucura, Foucault (2010) explicita a representação que se tinha do sujeito homossexual à época e lugar pesquisados. $\mathrm{O}$ anormal era aquele homem que possui traços de feminilidade, ora visto como doente mental ora como criminoso. Pode-se perceber, a exemplo disso, ao analisar o relatório de sentença de um crime, que as características dos criminosos assinalam "[...] imoralidade, tendências, papéis de gênero, punição religiosa pelo vício, invertidos, indefinição de papeis sexuais, Sodoma e Gomorra" (FOUCAULT, 2010, p. 6). Dito isso, tais enunciados permitem contextualizar suas existências no contexto em que os sujeitos que narraram suas existências puderam ser estudantes.

Os reflexos da anormalidade (FOUCAULT, 2010) e da infâmia (FOUCAULT, 2003) podem ser vistos a partir das diferentes situações de violências físicas e não físicas (RIOS, 2009) que o sujeito da memória 6 passou. Tais situações visam anular a diferença e demarcá-la como pertencente ao território do (in)vivível, do impossível, do desnecessário aos olhos moralistas que indicam um tratamento hostilizado à época de sua escolarização.

O sujeito da memória 6 considera que o problema maior foi a questão da carta, mas o que fica evidente é a utilização de uma pessoa homossexual como bode expiatório de naturalização de ofensas e violências físicas. Ao dizer que foi remanejado, o sujeito da memória 6 reconhece que viveu algo errado. Sua diferença ficou exposta. Por mais que possa ser uma forma de proteção frente à amplitude e gravidade das agressões, ainda assim é necessário que a escola utilizasse de uma série de recursos pedagógicos para conter a propagação de práticas de violências físicas e não físicas sobre/para/por pessoas homossexuais.

Observa-se que a escola pode ter apagado esse sujeito daquele momento. $O$ local de produção de rupturas foi proposto. A partir desse acontecimento, a escola poderia assumir uma nova explicação comprometida com a redução e combate de homofobia que estava se reproduzindo sobre as relações do ambiente escolar, mas resolveu agir com o apagamento desse sujeito para que sua expressão não tivesse condições de ser problematizada.

Há que se ressaltar que, por mais que a leitura possa ser rígida, a escola procedeu com o silenciamento. Não promoveu rupturas possíveis para que práticas heteronormativas não adquirissem capilaridade no contexto de produção de cultura, linguagens e sentimentos ali em fase de construção. Entre acusações, apontamentos, violências físicas e etc., pessoas homossexuais constituem-se como sujeito cuja diferença é sinônimo de cerceamento dos direitos. Direito de ter acesso e permanência em serviços públicos que qualificam a condição de cidadania. A escola opta por naturalizar as violências e silenciar os homossexuais diante da novidade produzida pelos seus corpos.

Lidar com as diferentes expressões da sexualidade e do gênero na escola, segundo Seffner (2009), impõe pensar em que situações pedagógicas teremos que reconstruir outros discursos, espaço, rotina e sobretudo, a percepção que os sujeitos criam quando utilizam de sentidos preconceituosos para se referir mesmo que ressoar como brincadeira aos/as outros/as pessoas. Assim, Seffner (2009, p. 132) propõe: 
A primeira é a abolição das piadas e das manifestações sexistas, tão comuns entre professores e professoras, acerca dos alunos e das alunas "diferentes" dos padrões heterossexuais ditos "normais". Não é possível educar num ambiente de falta de respeito, e a agressão verbal e até mesmo física - tem sido uma arma de expulsão de indivíduos que não se enquadram na regra heteronormatividade. É necessário construir um ambiente de respeito e aceitação, o que não significa permitir que todos os desejos dos alunos em relação à vida amorosa

e
particularmente sexual sejam admitidos na escola.

Observa-se que as mudanças precisam ser iniciadas no ambiente escolar, considerando a presença mais e mais constante do entrecruzamento e soma de diferentes demarcadores sociais que podem diminuir a cidadania das pessoas. Romper com o tratamento que ridiculariza uma pessoa homossexual, por exemplo, é um assunto presente na adoção de práticas pedagógicas que combatam a homofobia, além de discutir a questão da homofobia interseccionada com outro assunto como o racismo, território vivido, renda e etc.

Trazer essas diferentes experiências de constituição de sujeitos na articulação com o ambiente escolar é uma forma de problematizar como a homofobia se fazia presente na vida escolar desses sujeitos. Estudos posteriores e que partam de histórias, narrativas e problematizações da vida homossexual no ambiente escolar precisam encontrar um caminho possível para tornar tais vidas possíveis. Essas vidas precisam ocupar o status de preservada também pelos modelos que normatizam padrões de existência.

Cada período histórico em que esses sujeitos tiveram contato com a escola nos oportuniza acessar maneiras de entender barreiras produzidas para se viver a diferença da sexualidade padrão. No entanto, não podemos deixar com que a padronização de corpos heteronormativos impeçam que outros corpos construídos sobre outras artesanias deixam de ter sentido para as relações de poder que criam o normal. Evitar que a educação acredite que tais práticas são naturalizadas e outras não.

Assim, a ideia é de que as práticas dos/das professores/as possam expressar formas de engajamento definitivo no combate à homofobia, onde possam ser, na concepção de Junqueira (2009, p. 36), “[...] construídos novos padrões de aprendizado, convivência, produção e transmissão de conhecimento, sobretudo se forem ali subvertidos ou abalados valores, crenças, representações e práticas associados a preconceitos, discriminações e violências de ordem racista, sexista, misógina e homofóbica".

A ideia é realizar um conjunto de educações que não combinem com o pacto de silenciamento diante das diferenças. Agir pedagogicamente a partir da defesa do direito de experimentar a liberdade de ser diferente e poder conviver com outros diferentes. Isso significa deslocar a ideia de padrão instituído pela sociedade para entender-se como parte de uma sociedade que precisa acolher o padrão que eu crio para a minha liberdade de expressar-se cidadão/ã. Se no tocante a esse aspecto, a minha sexualidade for diferente, ela é produto da minha diferença e não terá que ser diminuída frente à outra considerada dominante como usualmente acontece.

\section{CONSIDERAÇÕES FINAIS}

É notória uma variedade de experiências da diferença referente à sexualidade. Experiências de estratégias que visam invalidar a homossexualidade como uma expressão da sexualidade que pode ser elevada ao terreno do possível. Os sujeitos participantes da pesquisa apresentam em níveis moderados ou cruéis, memórias do tempo de escolarização. Suas experiências demonstram negações nas escolas, nas famílias, na vida, dentre outras.

Evidentemente é presente o silenciamento como uma forma de expressar a violência não física. Não se faz nada diante de práticas de segregação, falta de respeito com a vida diferente, opta-se por abafamento em detrimento do agir pedagogicamente diante desses contextos em que a homofobia está se edificando.

O movimento proposto no contexto da apresentação dessas histórias de vida foi o de 
fazê-las vivas para a educação. Problematizar os sentidos construídos pelos sujeitos nos silêncios oferecidos pelas suas passagens nos ambientes escolares de diferentes décadas entre o fim do século XX e início do século XXI. Tais histórias permitem-nos entendê-las como sendo passíveis de serem evidenciadas ou esquecidas como se nada tivesse acontecido. Sobre essa última prática, o esquecimento é uma forma de posicionamento. Um posicionamento que, por sua vez, não caracteriza que a pessoa homossexual sofra quaisquer tipos de homofobia e que, sobretudo, a criminalização ou adoção de práticas de prevenção via saber escolar científico representa um problema, uma ameaça.

A ameaça, nesse sentido, demonstra a atitude preconceituosa que paira sobre o projeto societário vigente que desconsidera corpos diferentes. Há a presença do medo de que esse projeto societário sofra interferências no contato com a diferença. De modo cruel, o processo de apagamento de pessoas homossexuais, lésbicas, bissexuais e trans do espaço público tem se tornado intenso. O reflexo catastrófico disso impõe pensar filosoficamente sobre qual política da vida é criada para que se possa ser, viver e conviver em sociedade livremente, sem que forças dominantes encarem pessoas diferentes como uma ameaça aos seus projetos societários.

Leva a confirmar que a manifestação arbitrária da heterossexualidade presente nas relações escolares como princípio de existência e de tratamento do/a alunado/a revela o alijamento das expressões da diversidade sexual que se fazem presentes nas escolas. Tal situação potencializa as vias de exclusão da permanência dessas pessoas no ambiente escolar porque associada às questões étnico-raciais, de renda, religiosas, dentre outras intensificam a produção do fracasso existencial, escolar e social.

O que fica visível é o fato de que a reflexão emergente desse estudo fundamenta-se na exposição de memórias existenciais cuja passagem que fizeram pelo ambiente escolar cada um na sua época - sofreu com o crivo da heteronormatividade e com isso, perderam o sentido de uma existência inovada que poderiam fazer de seus corpos, de suas sexualidades, de suas vidas. O espaço escolar, então, representa um lugar privilegiado de instrumentalização de projetos societários que, em muitos casos, não estão consoantes com 0 modelo de enquadramento que pessoas diferentes fazem de si.
Para uma ação que acolha o/a estudante homossexual na unidade escolar é preciso se aproximar de um projeto societário aberto à novidade que a diferença nos traz. Isso visa produzir uma ação de descolamento, despregamento, desvencilhamento do corpo e da existência moralmente enquadrada como modelo que nos foram impostas europeizantemente. Esse processo de despregamento da moralização de corpos oportuniza com que eles tenham mais vazão de experimentação ao novo; traz assim, novas possibilidades para 0 ato educativo compromissado com a formação humana.

Conclui-se que a sexualidade é um assunto que também compõe a construção da subjetividade dos/das alunos/as e a escola enquanto uma instituição que discursa sobre a formação do humano pode trabalhar na criação de saberes escolares que conjugam o assunto da sexualidade com a equidade, ética e pluralidade de constituição do ser. Isso produz pertencimento e diz aos/as estudantes homossexuais que criar projetos ou itinerários formativos por meio da educação é possível.

\section{REFERÊNCIAS}

BENTO, Berenice. Na escola se aprende que a diferença faz a diferença. Estudos Feministas. Florianópolis, v. 19, n. 2, p. 549-559, 2011. Disponível em: https://doi.org/10.1590/S0104026X2011000200016 . Acesso em: 03 set. 2019.

BORRILLO, Daniel. Homofobia: história e crítica de um conceito. Belo Horizonte: Autentica, 2010.

BUTLER, Judith. Vida precária. Contemporânea. São Carlos, v. 1, n. 1, p. 13-33, 2011. Disponível em:

http://www.contemporanea.ufscar.br/index.php/ contemporanea/article/view/18/3. Acesso em: 3 set. 2019.

BUTLER, Judith. Relata a si mesmo: crítica da violência ética. Belo Horizonte: Autêntica, 2015.

CORACINI, Maria José. A celebração do outro: arquivo, memória e identidade: línguas (materna e estrangeira), plurilinguismo e tradução. Campinas: Mercado das Letras, 2007.

CRUZ E SOUZA, João da. Poesias Completas de Cruz e Sousa. Rio de Janeiro: Ediouro, 1951, 
DELEUZE, Gilles. Foucault. São Paulo: Brasiliense, 2005.

DINIS, Nilson F. Homofobia e educação: quando a omissão também é sinônimo de violência. Educar em Revista. Curitiba, n. 39, p. 39-50, 2011. Disponível em: http://www.scielo.br/pdf/er/n39/n39a04.pdf.

Acesso em: 12 ago. 2019.

https://doi.org/10.1590/S0104$\underline{40602011000100004}$

FOUCAULT, Michel. Vigiar e Punir. 27ạ ed. Petrópolis: Vozes, 1987.

FOUCAULT, Michel. A Arqueologia do saber. 3a ed. Rio de Janeiro: Forense universitária, 1972.

FOUCAULT, Michel. A vida dos homens infames. In: FOUCAULT, Michel. Ditos e escritos IV. Rio de Janeiro: Forense Universitária, 2003, p. 203-222.

FOUCAULT, Michel. Os anormais. Tradução Eduardo Brandão. São Paulo: WMF Martins Fontes, 2010

GUATTARI, Felix; ROLNIK, Suely. Micropolítica: cartografias do desejo. 4 ed. Petrópolis, RJ: Vozes, 1996.

JESUS, Jaqueline G. de. Orientações sobre identidade de gênero: conceitos e termos. 2 ed. Brasília: UNB, 2012.

JUNQUEIRA, Rogério D. Homofobia nas escolas: um problema de todos. In: JUNQUEIRA, Rogério D. Diversidade sexual na educação: problematização sobre a homofobia nas escolas. Brasília: MEC/SECAD, 2009. p. 13-52.

JUNQUEIRA, Rogério D. A pedagogia do armário: a normatividade em ação. Revista Retratos da Escola, Brasília, v. 7, n. 13, p. 481-498, jul./dez. $2013 . \quad$ Disponível em: http://retratosdaescola.emnuvens.com.br/rde/ar ticle/download/320/490 . Acessado em: 30 ago. 2019.

LOURO, Guacira L. Heteronormatividade e homofobia. In: JUNQUEIRA, Rogério D. Diversidade sexual na educação: problematização sobre a homofobia nas escolas. Brasília: MEC/SECAD, 2009. p. 85-94.
MEYER, Dagmar E; PARAISO, Marlucy A. Metodologias de pesquisas pós-críticas em educação. 2 ed. Belo Horizonte, MG: Mazza Edições, 2014. p. 49-64.

OLIVEIRA JÚNIOR, Isaias B; MAIO, Eliane R. "Não vai ser permitido a nenhum órgão do Governo fazer propaganda de opções sexuais": o discurso inaugural do "desagendamento" do kit gay do MEC. Revista e-Curriculum, São Paulo, v. 15, n. 1, p. 125-152, 2017. Disponível em: https://revistas.pucsp.br/index.php/curriculum/a rticle/view/23427. Acesso em: 30 out. 2019. https://doi.org/10.23925/1809-

3876.2017v15i1p125-152

QUEIROZ, Norcirio S. Vivências da homofobia no período escolar: significações na idade adulta. 2018. 131 f. Dissertação (Mestrado em Psicologia) - Universidade Federal do Amazonas, Manaus, 2018.

RIOS, Roger R. Homofobia na perspectiva dos direitos humanos e nos contextos dos estudos sobre preconceito e discriminação. In: JUNQUEIRA, Rogério D. Diversidade sexual na educação: problematização sobre a homofobia nas escolas. Brasília: MEC/SECAD, 2009. p. 53-84.

SCHULMAN, Sarah. Homofobia familiar: uma experiência em busca de reconhecimento. Bagoas

- Estudos gays: gêneros e sexualidades. Rio Grande do Norte, v. 4, n. 05, p. 58-78, 2012. Disponível em: https://periodicos.ufrn.br/bagoas/article/view/23 12. Acesso em: 03 set. 2019.

SEFFNER, Fernando. Equívocos e armadilhas na articulação entre diversidade sexual e políticas de inclusão escolar. In: JUNQUEIRA, Rogério D. Diversidade sexual na educação: problematização sobre a homofobia nas escolas. Brasília: MEC/SECAD, 2009. p. 125- 140.

SILVA, Fernando G. O. da. Vozes (des)veladas... Memórias de homossexuais sobre práticas escolares. 2015. 143 f. Dissertação (Mestrado em Educação) - Universidade Estadual de Mato Grosso do Sul, Paranaíba, 2015. 